\title{
Research on Building Energy Saving Design of Large Hotel in Urumqi
}

\author{
Haiyue Zhang ${ }^{1, a}$, Yang Chen ${ }^{1}$ and Qing Qin ${ }^{1}$ \\ ${ }^{1}$ School of Human Settlement and Civil Engineering, Xi' an Jiaotong University, Xi'an 710049, China
}

\begin{abstract}
In Urumqi, China, the occupancy rate of hotels during the low season is quite different from that of high season. This phenomenon can result in wasting energy. However, most energy saving design standards don't take seasonal use characteristics of buildings into consideration. This paper focused on the energy saving design based on seasonal use patterns for big hotels in Urumqi. Combining time-variation characteristics with the unique climate this study explored a different approach to energy management. Design strategies for big hotels in the Urumqi region were developed according to use patterns and climatic conditions, considering thermal, wind and luminous factors. This study provides design ideas for big hotels in temperate continental climate areas based on this alternative approach.
\end{abstract}

\section{Climate characteristic of Urumqi}

Urumqi is located in the hinterland of the Eurasian continent, to the north of Tianshan Mountain and in the south of Junggar basin. It belongs to temperate continental climate region. Spring and autumn periods are short with long summer and winter periods. The temperature difference between both summer and winter and between day and night are significant.

The thermotechnical zone of Urumqi belongs to severe cold $\mathrm{C}$ zone in China in winter. At the same time summer temperatures are significantly warmed but they are still considered cool [1]. The number of heating degree days per year are $4530.9^{\circ} \mathrm{C} \cdot \mathrm{d}$, while the air condition days are only $32.6{ }^{\circ} \mathrm{C} \cdot \mathrm{d}$. The average temperature in the coldest month ranges from $-15^{\circ} \mathrm{C}$ to $20^{\circ} \mathrm{C}$, with the extreme low temperatures as cold as $43.5^{\circ} \mathrm{C}$. The average temperature in the hottest month is only $25^{\circ} \mathrm{C}$, with the extreme high temperatures reaching $42.8^{\circ} \mathrm{C}$. North and northeast winds usually occur in winter, while east winds usually occur in summer. The highest speeds occur in spring and autumn, with wind speeds reaching $30 \mathrm{~m} / \mathrm{s}$. Urumqi is located in solar energy area II, in China, indicating solar energy can be used as a significant resource [2].

\section{The present situation of large hotels in Urumqi}

\subsection{The current situation of building energy saving design for large hotels in Urumqi}

With the rapid development of Xinjiang's tourism industry, the number of hotels in Urumqi is growing rapidly. The phenomenon of high energy cost due to energy waste is getting worse in large hotels with seasonal occupation patterns.

\subsubsection{The development of existing large hotels energy efficiency design in Urumqi}

Due to the harsh climate, research in energy saving design in Xinjiang has always been at the forefront of China. Most of the big hotels in this region were designed and built in recent decades. Therefore, according to the standard of local public building energy saving design, most big hotels meet the requirement for annual total energy consumption. Their energy consumption is half of those hotels without energy saving measures. However, in order to make buildings save energy more economically, the newly revised energy saving design code for public buildings in Xinjiang gives priority to passive energy saving measures.

\subsubsection{The problem of energy efficient design in existing large hotels in Urumqi}

Almost all large hotels in Urumqi achieve the requirement of the local standard, which is published in 2006. This standard, however, focuses mainly on public buildings. It does not take into consideration the seasonal use patterns of hotels in Urumqi. This causes a serious waste of energy during the daily operation of hotels during low occupancy periods.

Because Urumqi region is quite cold, energy gain problems for western exposure haven't been addressed in the standard. However, the sunshine intensity in Urumqi is often very high in the summer. Indoor temperature will be too high to be comfortable because 
of the spaces associated with western exposure in summer.

The public areas in hotels, including corridors and hallways, suffer from poor ventilation and lighting. In response, hotels have to use more energy to improve the indoor environment with mechanical systems even during the daylight hours.

\subsection{Application characteristics of Urumqi hotel}

Energy saving design for hotels should be related to their use pattern. This paper mainly concentrates on proposing energy saving strategies that match the usage characteristic of hotels. As a tourist city, Urumqi has great variation in hotel use patterns between the low season and the high season [3].

The high season is from May to October every year, when the number of tourists is quite large and occupancy in hotels is almost $100 \%$. In the low season, the number of tourists declines sharply to an occupancy rate which is only $50 \%$. The heating period of Urumqi is from October to April, which means the whole heating period is the tourism low season. Nearly half of the rooms are idle, and the utilization rate of public areas such as restaurants, entertainment and leisure areas, fitness areas and conference rooms also decreases significantly. The seasonal tourism situation dramatically affect the utilization rate of hotel buildings. Combining this point with energy saving design can improve the energy efficiency of large hotel buildings in this area [4].

Urumqi has a very strict security requirements. Every public building's entrance and exit is equipped with a safety inspection area, while the existing architectural design does not take the question of energy usage into consideration. The safety inspection area is only marked with red line. It's neither beneficial for convenience nor for safety. The safety inspection area can be combined with anteroom at design time. It can realize the situation that the front gate is closed while the back gate is open in anteroom. Thus the anteroom can achieve the effect of thermal insulation more efficiently.

\section{Building energy consumption analysis of large hotels in Urumqi}

The hotel business is an industry with high-energy consumption. Four or five star hotel meet the basic needs of central heating and refrigeration, but also waste significant amounts of energy in the process. According to the survey, most of the hotels in Urumqi still use coalfired boilers for heating. A five-star hotel, that covers an area of eighty thousand to one hundred thousand square meters, consumes about one hundred and fifty thousand tons of standard coal throughout the year. This consumption of energy is nearly equal to a big factory. Energy consumption has become an economic challenge for the development of the hotel industry [4,5]. It has also become a key problem to save energy and protect the environment all over the world.

The heating period of Urumqi is long and the refrigeration period is relatively short. So, most energy consumption occurs in heating period throughout the year. The lack of alignment between occupancy rates and the heating period is the main cause of energy consumption problems in Urumqi. In addition the lack of protection from western exposure negatively impacting comfort of spaces associated with these exposures, along with the need to utilize mechanical methods to adjust other indoor environments like corridors and hallways, causes additional energy waste.

\section{Design strategy of large hotel energy saving in Urumqi}

This study survey summarized the seasonal usage characteristics of hotel buildings, revealing it as a significant design problem in Urumqi. In response, this study proposes design strategies for big hotels in Urumqi by focusing on design responses to the thermal, wind and luminous environment in relation to the energy challenges of hotel buildings.

\subsection{Design strategy of thermal environment}

\subsubsection{The concept of using partition in different seasons}

As the occupancy rate of the large hotel buildings in the Urumqi is only about $50 \%$ in the heating period, the use rate of the corresponding restaurants, recreational and conference and other public areas are also reduced. The concept of partitioning off underutilized space in different seasons can address this challenge and achieve the best energy saving effect.

Bedrooms of traditional residence in Xinjiang region can be separated into summer bedroom and winter bedroom to achieve different requirement for comfort in different seasons with the least cost. The concept of using partition in different seasons draws lessons from the ecological energy saving wisdom of traditional architecture.

At first, guest rooms should be separated into Summer Guest Rooms and Winter Guest Rooms. The Summer Guest Rooms are only available in high season and Winter Guest Rooms are available the whole year. Considering the fact that the occupancy rate halves in winter, it's suggested that Winter Guest Rooms should account for $55 \%--60 \%$ of the total number of guest rooms and Summer Guest Rooms should account for $40 \%--45 \%$. The number of Winter Guest Room is slightly more than that of Summer Guest Room. This will provide a reasonable accommodation for the elasticity of demand for rooms in the off season. It can also be good for putting as many rooms at the best direction as possible(Figure 1.). When winter comes, Summer Guest Rooms are closed, and the indoor temperature can be maintain at $5^{\circ} \mathrm{C}--10^{\circ} \mathrm{C}$ instead of $21--$ $24{ }^{\circ} \mathrm{C}$, just like the storage space. Under heating condition, the indoor calculation temperature decreases by $1{ }^{\circ} \mathrm{C}$, the energy consumption can be reduced by $5 \%$ to $10 \%$. Closing Summer Guest Rooms can save a lot of 
energy cost for hotels. Moreover, Summer Guest Rooms, located at the north or northeast of the building, can be used as temperature damping areas to resist winter wind infiltration and reduce heat loss in heating area. Winter Guest Rooms should be set in the south of the building to achieve enough sunshine to meet the demand for light and heat.

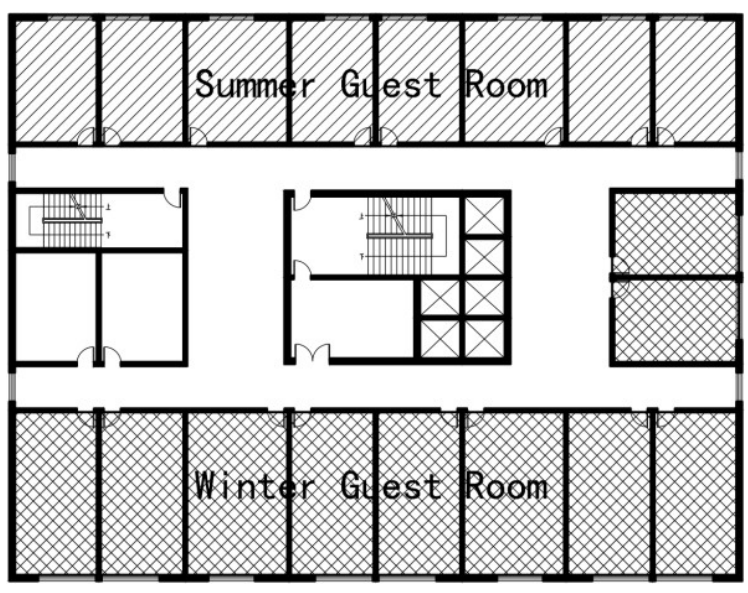

Figure 1. Plan Sketch of Room Layer.

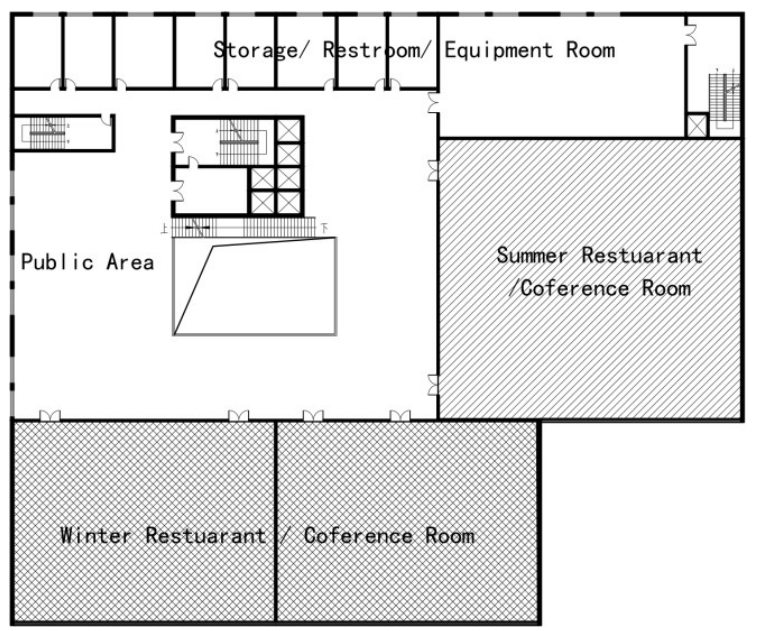

Figure 2. Plan Sketch of Public Layer.

The occupancy rate of public space also drops in winter. Just like the guest room space, public space, such as dining hall, fitting room and meeting room should be separated into "winter zone" and "summer zone" , too(Figure 1.). $30 \%-40 \%$ of these public spaces can be closed in winter, and the indoor temperature can be maintained at $5^{\circ} \mathrm{C}--10^{\circ} \mathrm{C}$ instead of $20--23^{\circ} \mathrm{C}$. They can also be placed at the north of the buildings acting as temperature damping area.

\subsubsection{The concept of using partition in different function}

According to the different temperature requirements of space, reasonable spatial arrangement of the physical environment can be functionally attractive and reduce energy consumption. Different spaces require different temperatures in big hotels. In winter, the guest room temperature should be maintained at $20--24^{\circ} \mathrm{C}$ all day. The temperature of lobby, atrium and hall should be at 19-- $22^{\circ} \mathrm{C}$ all day. However, the temperature of business space and service space should only be maintained at 20$-23{ }^{\circ} \mathrm{C}$ during the periods when they are used. Temperature of fitting rooms should be at $18--20^{\circ} \mathrm{C}$ during use period. Temperature of other places, such as"summer zone", parking lot and storage room, can just be kept at $5{ }^{\circ} \mathrm{C}$. The relationship between use patterns and temperature of every space can be classified into 6 categories. The details of every category are shown in Table 1.

\subsubsection{Some other local design strategy}

Traditional, semi-underground space in the residences of Xinjiang, are often used for cool in summer and to resist cold current in winter [6]. The design of hotels can draw lessons from this feature. It's suggested that the outdoor space of hotels can be designed as sunken plaza, which is connected with underground floor. Underground floor can be used as entertainment space. It will be cool in summer and warm in winter.

Double balcony is also quite suitable for hotels. The north balcony can act as temperature damping area to resist winter wind infiltration and the south balcony can act as sunroom to heat the room continuously. The balconies on both sides are closed at night to reduce the dissipation of indoor heat and block the infiltration of cold air.

\subsection{Design strategy of wind environment}

In Urumqi, wind speed in spring and automn is much higher than any other time of the year, and sand dust problems are a common occurrence. In order to make the building have appropriate and positive ventilation, the atrium of the hotel can be used more fully. Taking advantage of natural convection air flows, guest rooms and circulation spaces will be able to enjoy better ventilation, and reduce the intrusion of dust into the indoor air environment.

Another benefit of the development of the atrium space with landscape, will be the improvement of indoor air quality and increased use of public stairs reducing guest's dependence on elevators.

As mentioned above, the combination of safety inspection area and anteroom can reduce heat loss in hotel. Entry areas should avoid facing winter winds and the distance between front doors and back doors should be large enough to temper air flow when the doors are being used. This will facility the use of this space for more than just security inspection. Because the visitors flow rate in high level hotels is big, two security check channels should be set at least. According to the position of doors, anterooms can be classified into corner type (Figure 3.) and penetration type (Figure 4.). The corner type does better in addressing concerns related to the wind than penetration type. 
Table 1: Statistical tables for the use of each space in winter

\begin{tabular}{|c|c|c|c|c|c|c|}
\hline & Temperature & Using Period & Frequency & category & Area occupation ratio & Orientation \\
\hline Winter Guest Room & $20-24^{\circ} \mathrm{C}$ & Whole Day & highest & A & $30 \%$ & South \\
\hline Lobby Stalls & $19-22^{\circ} \mathrm{C}$ & Whole Day & highest & B & $5 \%$ & $\begin{array}{c}\text { South } \\
\text { Southeast } \\
\text { Southwest }\end{array}$ \\
\hline Conference Room & $20-23^{\circ} \mathrm{C}$ & $9: 00-20: 00$ & high & $\mathrm{C}$ & $5-8 \%$ & South \\
\hline $\begin{array}{l}\text { Restaurant } \\
\text { Banquet Hall }\end{array}$ & $20-23^{\circ} \mathrm{C}$ & $\begin{array}{c}\text { Breakfast } \\
\text { 07:00-11:00 } \\
\text { Dinner } \\
\text { 12:00-23:00 }\end{array}$ & high & $\mathrm{D}$ & $5-8 \%$ & $\begin{array}{c}\text { South } \\
\text { Southeast } \\
\text { Southwest }\end{array}$ \\
\hline $\begin{array}{l}\text { Business } \\
\text { Service }\end{array}$ & $20-23^{\circ} \mathrm{C}$ & $10: 00-18: 00$ & high & $\mathrm{E}$ & $1 \%$ & South \\
\hline $\begin{array}{l}\text { Summer Guest Room } \\
\text { Conference Room } \\
\text { Restaurant }\end{array}$ & $5-10^{\circ} \mathrm{C}$ & Whole Day & low & $\mathrm{F}$ & $\begin{array}{l}20 \% \\
2-5 \% \\
2-5 \% \\
\end{array}$ & $\begin{array}{c}\text { North } \\
\text { Northeast }\end{array}$ \\
\hline $\begin{array}{l}\text { Storage Equipment } \\
\text { Room Parking }\end{array}$ & $5-10^{\circ} \mathrm{C}$ & Whole Day & low & $\mathrm{F}$ & $\begin{array}{c}5 \% \\
3 \% \\
10 \%\end{array}$ & $\begin{array}{c}\text { North } \\
\text { Northeast }\end{array}$ \\
\hline
\end{tabular}

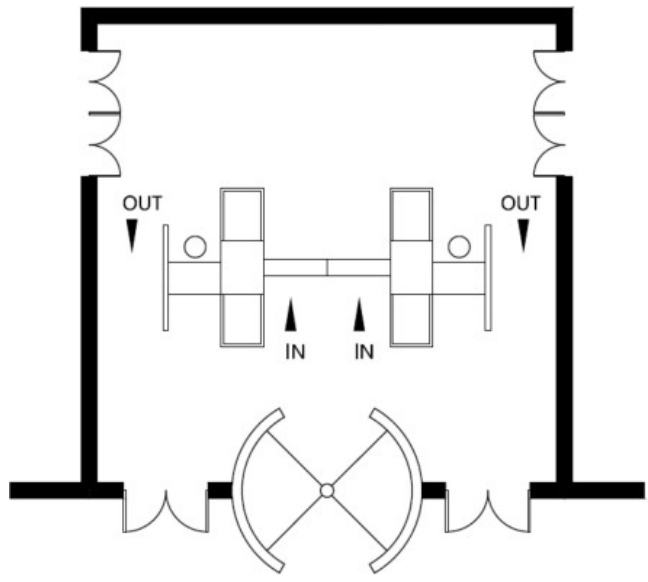

Figure 3. Corner Type.

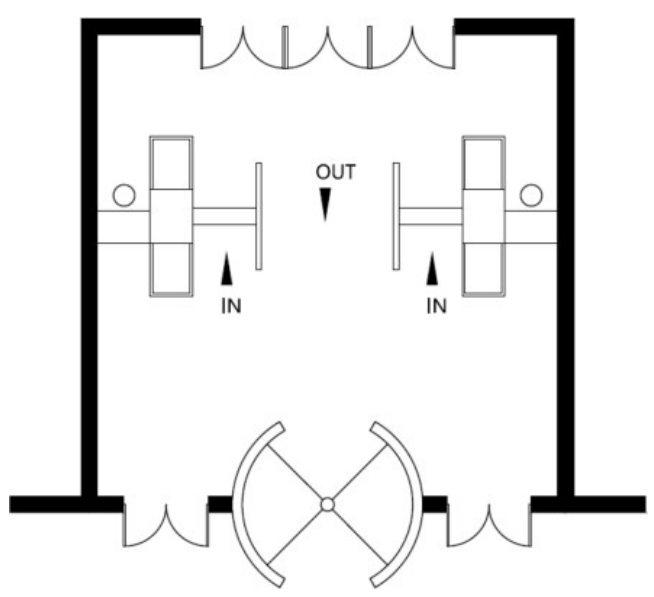

Figure 4. Penetration Type.

\subsection{Design strategy for utilization of passive solar}

Both atrium and sunroom should be used to make full use of solar energy in winter. The sun can provide heat continuously both to the side and the centre of the building. Atrium can also meet the basic lighting demand of large-scale and large-depth buildings. Horizontal skylights can be shaded with translucent tarpaulin in summer to facilitate lighting needs while avoiding overheating the interior. In addition, light sensor technology can be used in corridor, when necessary, to reduce energy consumption. Windowshades systems can be employed to handle the problem of western exposure in summer without affecting heating possibilities in winter.

\section{Conclusion}

Energy shortage has become a key problem in modern society in recent years. In response to this challenge, developing strategies to conserve energy in building design can be a significant contributer to solving this problem reducing energy consumption for the whole society [8].

The concept of using the seasonal partitioning of spaces in response to changing seasonal use patterns in occupancy rates can significantly contribute to energy saving in hotels.

In terms of address the energy implications of wind, the safety inspection area can be combined with anteroom. This dual use strategy can both meet the requirements of the security function and achieve energy savings at the same time.

This study can serve as a framework for the design of big hotels in Urumqi. Combine cost effective strategies 
for energy savings in response to the particular conditions of seasonal use patterns and common sense strategies for managing solar and wind impacts on the energy profiles of large hotels.

\section{Acknowledgment}

This work was supported by National Key R\&D Program of China (2016YFC0700400).

\section{References}

1. Design Standard for Energy Efficiency of Public Buildings, GB 50189-2015.

2. http://data.cma.cn/

3. H. Ying, "Evaluation of Tourism Climate Comfortableness in Xinjiang," Hubei Agricultural Sciences 20, 4510-4512, (2012)

4. W.Y. Zhou, "Analysis of Energy Consumption Level and Energy Saving Potential on Five-Star Hotel Building", Tianjin University, China, (2015).

5. L. Wang, L. Yang, "PRESENT ENERGY CONSUMPTION AND ENERGY SAVING ANALYSIS FOR STAR-RATED HOTELS IN XI'AN" ARCHITECTURE TECHNOLOGY, 5, 408-411, (2010).

6. X. Gao, D. Zhang, "Analysis of the rule of influence of hotel occupancy ratio on energy consumption", Electric Technology and Civil Engineering (ICETCE), 2011 International Conference on. IEEE, 1009-1014. (2011)

7. X.J. Zhao, S. G. Jiang, J. Yang, J.L. Zhang, "Research on Climatic Suitability and Optimization of Traditional Adobe House in Xinjiang Turpan area" Low Temperature Architecture Technology 8, 141-144, (2017).

8. V. Filimonau, J. Dickinson, D. Robbing, "Reviewing the carbon footprint analysis of hotels: Life Cycle Energy Analysis (LCEA) as a holistic method for carbon impact appraisal of tourist accommodation" Journal of cleaner production 17/18,1917-1930, (2011). 